
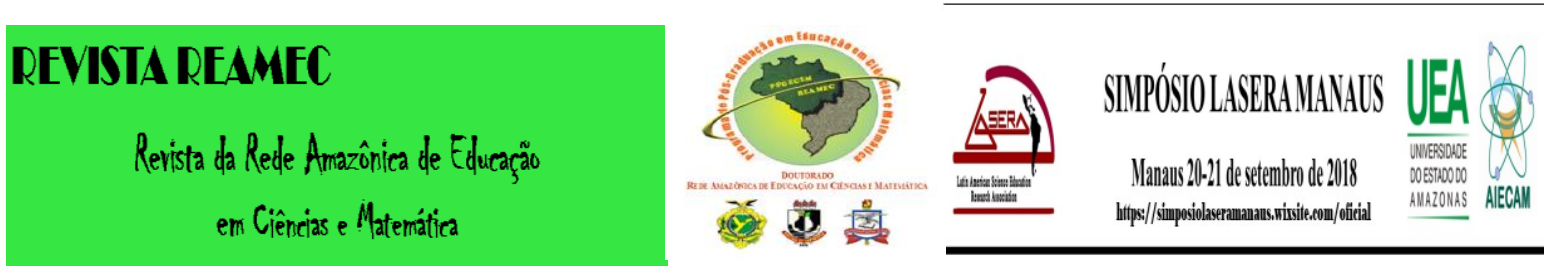

\title{
O ESTADO DA ARTE NA METODOLOGIA DA PESQUISA CIENTÍFICA NA FORMAÇÃO DE PROFESSORES DE BIOLOGIA NO BRASIL: UMA VISÃO BASEADA EM ANÁLISE DE TESES
}

Rúbia Darivanda da Silva Costa ${ }^{\mathrm{a}}$ Josefina Barrera Kalhil ${ }^{\mathbf{b}}$

Terezinha de Jesus Reis Vilas Boas

\section{A R T I C L E I N F O}

\section{Palavras chave:}

Formação de professores;

Biologia. Metodologia;

Paradigmas.

E-mail:

a rubia.dsc@gmail.com.

b josefinabk@gmail.com

Cterezinhajesusvc@gmail.com

\author{
R E S U M O
}

$\mathrm{O}$ artigo teve como finalidade investigar os paradigmas utilizados na produção acadêmica expressa em teses sobre a Formação de Professores de Biologia, defendidas em programas de pós-graduação de Educação e/ou Ensino de Ciências existentes no Brasil no período 2007-2016. Foram examinados 19 documentos. Acredita-se que este artigo poderá motivar reflexões sobre a formação de professores de Biologia, no âmbito do cenário nacional, além de permitir a análise e compreensão de como estão sendo aplicadas as metodologias para a coleta e estudo de dados das pesquisas desenvolvidas. $\mathrm{O}$ trabalho foi norteado pela identificação das abordagens metodológicas que foram aplicadas nos trabalhos. Nos resultados foram apresentados alguns termos utilizados na pesquisa científica para designar paradigma, além da identificação dos paradigmas mais utilizados pelos pesquisadores.

\section{INTRODUÇÃO}

As pesquisas voltadas para a Educação em Ciências, de um modo geral, têm promovido grandes avanços no cenário educacional brasileiro. Visto que as inúmeras investigações realizadas, principalmente, nos grupos de pesquisas dos cursos de pós-graduação da área, têm gerado uma elevada produção de conhecimento científico, o que tem proporcionado um aprimoramento e melhoramento na qualidade de ensino de Ciências, não somente na educação básica, mas também na educação superior, uma vez que é na academia que são formados os profissionais que atuam no ensino básico.

Assim, é possível perceber que nas últimas décadas, a estruturação das propostas relacionadas à educação em Ciências tem se consolidado; graças ao resultado do esforço conjunto de inúmeros pesquisadores e professores que primam pela formação de profissionais competentes e qualificados para o mercado educacional. Desse modo, grande parte desse 
esforço por ser observado na crescente produção científica resultante dos cursos de pósgraduação em Educação/Ensino de Ciências e Matemática que existem no território brasileiro.

Consequentemente, essa abundância de pesquisa na área, tem levando a um aumento de informações, que necessitam ser avaliadas e analisadas criteriosamente, para uma devida apreciação de seu rigor teórico e metodológico, visto que servirão de base para inúmeros estudos futuros. E, esse tipo de investigação possibilitará, também, uma análise, não somente da quantidade, mas, principalmente da qualidade dos produtos resultantes dos cursos de pósgraduação.

Nessa proposta de investigação da produção científica, focalizamos especificamente, a investigação das abordagens metodológicas utilizadas na produção acadêmica no Brasil, referente ao período de 2007 a 2016, produzidas nos programas de doutorado em Ensino e/ou Educação em Ciências, no banco de teses e dissertações da Coordenação de Aperfeiçoamento de Pessoal de Nível Superior (CAPES) e do Instituto Brasileiro de Informação em Ciência e Tecnologia (IBICT) que tenham como descritores a "Formação de Professores de Biologia" no título e/ou nas palavras-chaves.

A formação de professores, não apenas de Biologia, como das demais áreas do ensino, está cada vez mais se consolidando como um objeto de estudo nas pesquisas educacionais, tendo em vista os questionamentos e o aprofundamento de temáticas pertinentes à formação, a docência, aos conhecimentos, ao exercício, planos de carreira e trabalho dos educadores.

Contudo, ao ser realizado o levantamento preliminar do material correspondente, notamos que há pouca divulgação dessas produções, considerando que os bancos de dados não encontram-se atualizados, dificultando a aquisição do material necessário para a análise. Além disso, grande parte dos programas de pós-graduação não disponibilizam as teses dentro do próprio site do curso e, também não indicam um link da biblioteca da Instituição para facilitar e permitir o acesso a esse material.

Mas, para contornar essa situação, recorremos aos bancos de teses dos programas cadastrados e avaliados pela CAPES. Em relação aos artigos, foram adquiridos tanto aqueles inseridos na Scientific Eletronic Library Online (SciELO), quanto os que estavam disponíveis no Google Acadêmico, durante a etapa de levantamento de material disponível. Porém, estes últimos não foram utilizados neste trabalho devido serem produtos das teses que já haviam sido encontradas anteriormente. Acreditamos que este artigo poderá motivar reflexões sobre a 
formação de professores de Biologia, no âmbito do cenário nacional, além de permitir a investigação e compreensão de como estão sendo aplicadas as metodologias para a coleta e análise de dados das pesquisas desenvolvidas. Possibilitando a divulgação e a implementação de propostas metodológicas a serem seguidas para a melhoria do ensino de ciências e contribuições positivas para a formação de professores de biologia.

\section{METODOLOGIA}

A pesquisa do tipo Estado da Arte tem por finalidade fazer a revisão bibliográfica da produção acadêmica e/ou científica de certa temática, dentro de uma área específica do conhecimento (SILVA \& CARVALHO, 2014). Esse tipo de revisão faz a análise minuciosa e criteriosa da produção dentro de certo período cronológico, a fim de contribuir intelectual e socialmente, principalmente com a divulgação do que está sendo produzido na academia, no meio científico, e de que forma esse conhecimento está contribuindo positiva ou negativamente em determinada área de estudo.

O Estado da Arte permite avaliar a evolução e os movimentos da pesquisa em uma dada área do conhecimento, podendo manifestar a necessidade de prosseguir ou modificar o rumo das pesquisas, bem como das temáticas e metodologias. Possibilitando a análise dos principais resultados, das lacunas que ficaram abertas e, ainda, das áreas que não foram exploradas, a fim de identificar os espaços da produção, para poder sugerir, ou não, novas direções à investigação (MEGID NETO \& PACHECO, 2001; FERREIRA, 2002; SOARES, 2006), a fim de aprimorar a produção acadêmica e científica.

Esse trabalho surgiu da necessidade de investigar os paradigmas e abordagens metodológicas utilizadas nas produções acadêmicas e científicas e, para isso, inicialmente, foram selecionadas teses já defendidas e artigos publicados em revistas.

Mas, à medida que o material foi sendo analisado, notamos a dualidade de alguns trabalhos, uma vez que as teses oriundas dos cursos de pós-graduação, as quais podem ser consideradas, como sendo, o produto primário, foram apresentadas de forma sucinta em forma de artigo ou em eventos científicos/acadêmicos. Com isso, optamos por fazer o levantamento apenas das teses, a fim de evitar resultados equivocados ou tendenciosos na análise proposta. 
O período estabelecido da pesquisa foi de 2007 a 2016, ou seja, os últimos dez anos. A coleta de dados iniciou a partir da consulta aos Bancos de Teses e Dissertações da Coordenação de Aperfeiçoamento de Pessoal de Nível Superior (CAPES) e do Instituto Brasileiro de Informação em Ciência e Tecnologia (IBICT). Porém, ao notarmos a desatualização desses bancos, resolvemos acessar individualmente cada banco de Teses dos programas de pós-graduação em Educação e/ou Ensino em Ciências, cadastrados na plataforma Sucupira/CAPES, para garantir a segurança no levantamento dos trabalhos defendidos na área.

\section{RESULTADOS E DISCUSSÃO}

Nas últimas décadas a formação de professores tem sido um tema bastante discutido no cenário acadêmico nacional, esse fato deve-se principalmente ao grande aumento nas pesquisas sobre o assunto, apesar de poucas serem as mudanças e avanços observados nos curso de graduação que oferecem essa formação (AZEVEDO et al, 2012). Por outro lado, a expansão e consolidação dos cursos de pós-graduação em Educação e em Ensino de Ciências no Brasil, tem proporcionado um crescimento significativo nas pesquisas, principalmente as que estão relacionadas à Formação de Professores de Biologia.

Nesse sentido, Teixeira \& Megid Neto (2012), afirmam que:

A análise dos estudos relacionados ao foco temático 'Formação de Professores' permitiu a percepção das transformações que esse campo sofreu ao longo do tempo. Os documentos encaram a questão da formação docente assumindo diversas posições, desde estudos que consideram a formação de professores na perspectiva do treinamento e da ênfase no preparo técnico, passando pelas ideias de reciclagem e atualização, até a incorporação das ideias mais recentes sobre a formação de professores numa concepção reflexiva e crítica.

Como expressado anteriormente foi realizada uma breve análise de teses defendidas, contendo no título ou nas palavras chaves o termo "formação de professores de biologia". O levantamento foi concretizado entre os meses de março e abril de 2017, sendo encontrado um total de 19 teses, que abordavam à temática. Para uma melhor demonstração, organizou-se as produções encontradas, no Quadro 1, com suas principais informações.

Quadro 1 - Teses utilizadas para o estado da arte no contexto das metodologias.

Fonte: Costa (2017)

Revista REAMEC, Cuiabá - MT, V. 6, n. Especial, dez 2018, ISSN: 2318-6674 


\begin{tabular}{|c|c|c|c|c|}
\hline Programa/IES & Ano & Título & Paradigmas & $\begin{array}{c}\text { Classificação quanto } \\
\text { técnica/ instrumento } \\
\text { de coleta de dados }\end{array}$ \\
\hline $\begin{array}{c}\text { Educação } \\
\text { Cientifica e } \\
\text { Tecnológica/UFSC }\end{array}$ & 2007 & $\begin{array}{lll}\text { Fronteiras } & \text { do } & \text { conhecimento } \\
\text { escolar: O tema } & \text { da reprodução } \\
\text { assistida e } & \text { a Formação } \\
\text { Continuada de } & \text { professores de } \\
\text { Biologia } & & \end{array}$ & Qualitativo & Entrevista \\
\hline $\begin{array}{l}\text { Educação para a } \\
\text { Ciência/UNESP }\end{array}$ & 2008 & $\begin{array}{l}\text { Formação inicial de professores } \\
\text { de biologia: análise de uma } \\
\text { proposta de prática colaborativa } \\
\text { com o uso de computadores }\end{array}$ & Qualitativo & $\begin{array}{c}\text { Questionário } \\
\text { Pesquisa documental }\end{array}$ \\
\hline $\begin{array}{l}\text { Educação para a } \\
\text { Ciência/UNESP }\end{array}$ & 2009 & $\begin{array}{l}\text { Da capacitação em toxicologia, } \\
\text { psicofarmacologia e legislação na } \\
\text { formação inicial de professores } \\
\text { de Ciências e Biologia para a } \\
\text { prevenção educacional ao uso } \\
\text { abusivo de substâncias } \\
\text { psicoativas }\end{array}$ & Qualitativo & $\begin{array}{l}\text { Entrevistas semi- } \\
\text { estruturadas }\end{array}$ \\
\hline $\begin{array}{l}\text { Educação para a } \\
\text { Ciência/UNESP }\end{array}$ & 2010 & $\begin{array}{l}\text { Estratégias de ensino e } \\
\text { aprendizagem na formação } \\
\text { inicial de professores de ciências: } \\
\text { reflexões a partir de um curso de } \\
\text { licenciatura }\end{array}$ & Qualitativo & Estudo de caso \\
\hline $\begin{array}{l}\text { Educação para a } \\
\text { Ciência/UNESP }\end{array}$ & 2010 & $\begin{array}{l}\text { Uma proposta de formação } \\
\text { continuada de professores de } \\
\text { Biologia em Mato Grosso do Sul: } \\
\text { de manuais didáticos a obras } \\
\text { clássicas no estudo da evolução } \\
\text { biológica }\end{array}$ & Qualitativo & $\begin{array}{l}\text { Pesquisa-ação } \\
\text { Observação direta } \\
\text { Diário de campo } \\
\text { Relatos dos sujeitos }\end{array}$ \\
\hline $\begin{array}{l}\text { Educação para a } \\
\text { Ciência/UNESP }\end{array}$ & 2011 & $\begin{array}{l}\text { Investigação sobre um grupo de } \\
\text { pesquisa como espaço coletivo de } \\
\text { formação inicial de professores e } \\
\text { pesquisadores de biologia }\end{array}$ & Qualitativo & Investigação empírica \\
\hline $\begin{array}{l}\text { Educação para a } \\
\text { Ciência/UNESP }\end{array}$ & 2012 & $\begin{array}{l}\text { A (re)construção coletiva do } \\
\text { conceito de interação biológica: } \\
\text { contribuição para a epistemologia } \\
\text { da biologia e a formação de } \\
\text { pesquisadores e professores }\end{array}$ & Qualitativo & Investigação empírica \\
\hline $\begin{array}{l}\text { Educação para a } \\
\text { Ciência/UNESP }\end{array}$ & 2012 & $\begin{array}{l}\text { O estágio curricular } \\
\text { supervisionado na licenciatura } \\
\text { em ciências biológicas e a busca } \\
\text { pela experiência formativa: } \\
\text { aproximações e desafios }\end{array}$ & Qualitativo & $\begin{array}{c}\text { Questionários } \\
\text { Grupo focal } \\
\text { Narrativas } \\
\text { autobiográficas } \\
\text { Relatórios de estágio } \\
\text { Relatos da experiência }\end{array}$ \\
\hline $\begin{array}{l}\text { Ensino de Ciências } \\
\text { e Educação } \\
\text { Matemática/UEL }\end{array}$ & 2012 & $\begin{array}{l}\text { Formação inicial: o } \text { estágio } \\
\text { supervisionado segundo a visão } \\
\text { de acadêmicos de Ciências } \\
\text { Biológicas }\end{array}$ & Qualitativo & $\begin{array}{l}\text { Entrevistas áudio } \\
\text { gravadas } \\
\text { Análise textual } \\
\text { discursiva } \\
\end{array}$ \\
\hline $\begin{array}{l}\text { Ensino de Ciências } \\
\text { e Educação } \\
\text { Matemática/UEL }\end{array}$ & 2013 & $\begin{array}{l}\text { Formação Inicial e Perfil } \\
\text { Docente: um estudo por meio da } \\
\text { perspectiva de um instrumento de } \\
\text { análise da ação do professor em } \\
\text { sala de aula }\end{array}$ & Qualitativo & $\begin{array}{l}\text { Entrevistas áudio } \\
\text { gravadas } \\
\text { Análise textual } \\
\text { discursiva } \\
\end{array}$ \\
\hline
\end{tabular}

Revista REAMEC, Cuiabá - MT, V. 6, n. Especial, dez 2018, ISSN: 2318-6674

Revista do Programa de Doutorado da Rede Amazônica de Educação em Ciências e Matemática http://periodicoscientificos.ufmt.br/ojs/index.php/reamec 


\begin{tabular}{|c|c|c|c|c|}
\hline $\begin{array}{l}\text { Educação para a } \\
\text { Ciência e a } \\
\text { Matemática/UEM }\end{array}$ & 2013 & $\begin{array}{l}\text { Formação inicial do professor: } \\
\text { caracterização de um curso de } \\
\text { licenciatura em Ciências } \\
\text { Biológicas com base nas } \\
\text { Diretrizes Curriculares Nacionais }\end{array}$ & Qualitativo & $\begin{array}{l}\text { Estudo de caso } \\
\text { Questionários } \\
\text { Entrevistas }\end{array}$ \\
\hline $\begin{array}{l}\text { Ensino de Ciências } \\
\text { e Educação } \\
\text { Matemática/UEL }\end{array}$ & 2014 & $\begin{array}{l}\text { Axiologia relacional pedagógica } \\
\mathrm{e} \text { a formação inicial de } \\
\text { professores de biologia }\end{array}$ & Quanti-quali & Entrevistas \\
\hline $\begin{array}{c}\text { Educação em } \\
\text { Ciências e } \\
\text { Matemática } \\
\text { REAMEC } \\
\text { UFMT/UFPA/UE } \\
\text { A } \\
\end{array}$ & 2014 & \begin{tabular}{|lrrr} 
Currículo & e formação & de \\
professores & de & ciências & e \\
biologia: a & cultura & como eixo \\
articulador & dos & projetos \\
pedagógicos & & \\
\end{tabular} & Quanti-quali & $\begin{array}{c}\text { Observação } \\
\text { participante } \\
\text { Entrevistas } \\
\text { Análise documental } \\
\text { Análise de } \\
\text { Correspondência } \\
\end{array}$ \\
\hline $\begin{array}{c}\text { Educação } \\
\text { Científica e } \\
\text { Tecnológica/UFSC }\end{array}$ & 2014 & $\begin{array}{l}\text { As práticas pedagógicas e os } \\
\text { saberes da docência na formação } \\
\text { acadêmico-profissional em } \\
\text { Ciências Biológicas }\end{array}$ & Qualitativo & $\begin{array}{l}\text { Análise documental } \\
\text { Questionário } \\
\text { Entrevista } \\
\text { semiestruturada } \\
\text { Análise textual } \\
\text { discursiva } \\
\end{array}$ \\
\hline $\begin{array}{l}\text { Educação para a } \\
\text { Ciência/UNESP }\end{array}$ & 2015 & \begin{tabular}{lcr} 
Conceitos & \multicolumn{2}{r}{ ecológicos } \\
estruturantes & - investigando o \\
pensamento & de & futuros \\
professores & de & Ciências \\
Biológicas & & \\
\end{tabular} & Quanti-quali & $\begin{array}{l}\text { Escala do tipo Likert } \\
\text { Análise Multivariada }\end{array}$ \\
\hline $\begin{array}{l}\text { Educação para a } \\
\text { Ciência/UNESP }\end{array}$ & 2015 & $\begin{array}{l}\text { Uma pesquisa didático- } \\
\text { epistemológica na formação } \\
\text { inicial em Ciências Biológicas: } \\
\text { "como a evolução forjou a grande } \\
\text { quantidade de criaturas que } \\
\text { habitam o nosso planeta"? }\end{array}$ & Qualitativo & Questionário \\
\hline $\begin{array}{c}\text { Educação para a } \\
\text { Ciência e a } \\
\text { Matemática/UEM }\end{array}$ & 2015 & $\begin{array}{l}\text { A perspectiva de Ensino por } \\
\text { Pesquisa na formação inicial e } \\
\text { continuada de professores: a } \\
\text { Bacia Hidrográfica como tema de } \\
\text { estudo }\end{array}$ & Qualitativo & $\begin{array}{c}\text { Questionários } \\
\text { Gravações de áudio e } \\
\text { vídeo } \\
\text { Relatos e discussões } \\
\text { Análise do discurso } \\
\end{array}$ \\
\hline $\begin{array}{c}\text { Educação em } \\
\text { Ciências e } \\
\text { Matemática } \\
\text { REAMEC } \\
\text { UFMT/UFPA/UE } \\
\text { A } \\
\end{array}$ & 2015 & $\begin{array}{l}\text { Histórias de Vida de Formadores } \\
\text { de Professores de Ciências: } \\
\text { Paradigmas e Princípios } \\
\text { Científico-Pedagógicos de de } \\
\text { Formação Docente }\end{array}$ & Qualitativo & $\begin{array}{c}\text { Narrativas } \\
\text { Histórias de vida } \\
\text { Autobiografias } \\
\text { produzidas oralmente }\end{array}$ \\
\hline $\begin{array}{l}\text { Educação para a } \\
\text { Ciência/UNESP }\end{array}$ & 2016 & $\begin{array}{l}\text { Analogias quantitativas como } \\
\text { estratégia didática na formação } \\
\text { inicial de professores de Biologia } \\
\text { e Física }\end{array}$ & Quanti-quali & $\begin{array}{c}\text { Questionário } \\
\text { Análise estatística } \\
\text { descritiva } \\
\text { Observação } \\
\text { Análise do discurso } \\
\end{array}$ \\
\hline
\end{tabular}

De modo geral, em nenhuma das teses analisadas foi utilizado o termo paradigma para fazer referência ao padrão e/ou modelo metodológico a ser seguido para coleta e/ou análise de dados. O termo usado constantemente foram abordagem, procedimentos ou cunho metodológico. 


\section{REVISTA REAMEC}

Revista da Rede Amazônica de Edureação em Ciências e Matemática
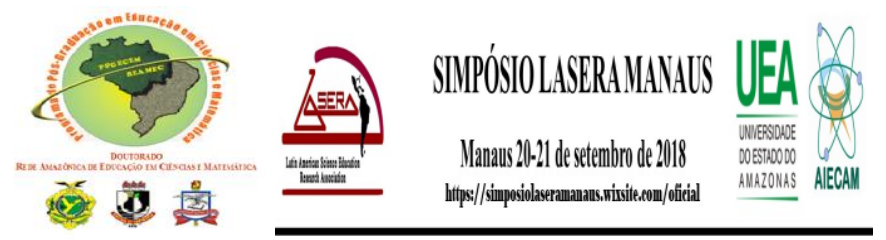

Ao analisar o Quadro 1, nota-se que a grande maioria da produção na temática em estudo foi encontrada na Universidade Estadual de São Paulo (UNESP), no programa Educação para a Ciência, o que pode ser constatado no Figura 1, seguida da Universidade Estadual de Londrina (UEL), na produção acadêmica do curso de doutorado em Ensino de Ciências e Educação Matemática. É importante salientar que não foram encontrados trabalhos abordando a temática em programas de pós-graduação em Universidades da região norte do país. Ficando assim a região Sul com a segunda posição em produção acadêmica voltada para a formação de professores de biologia.

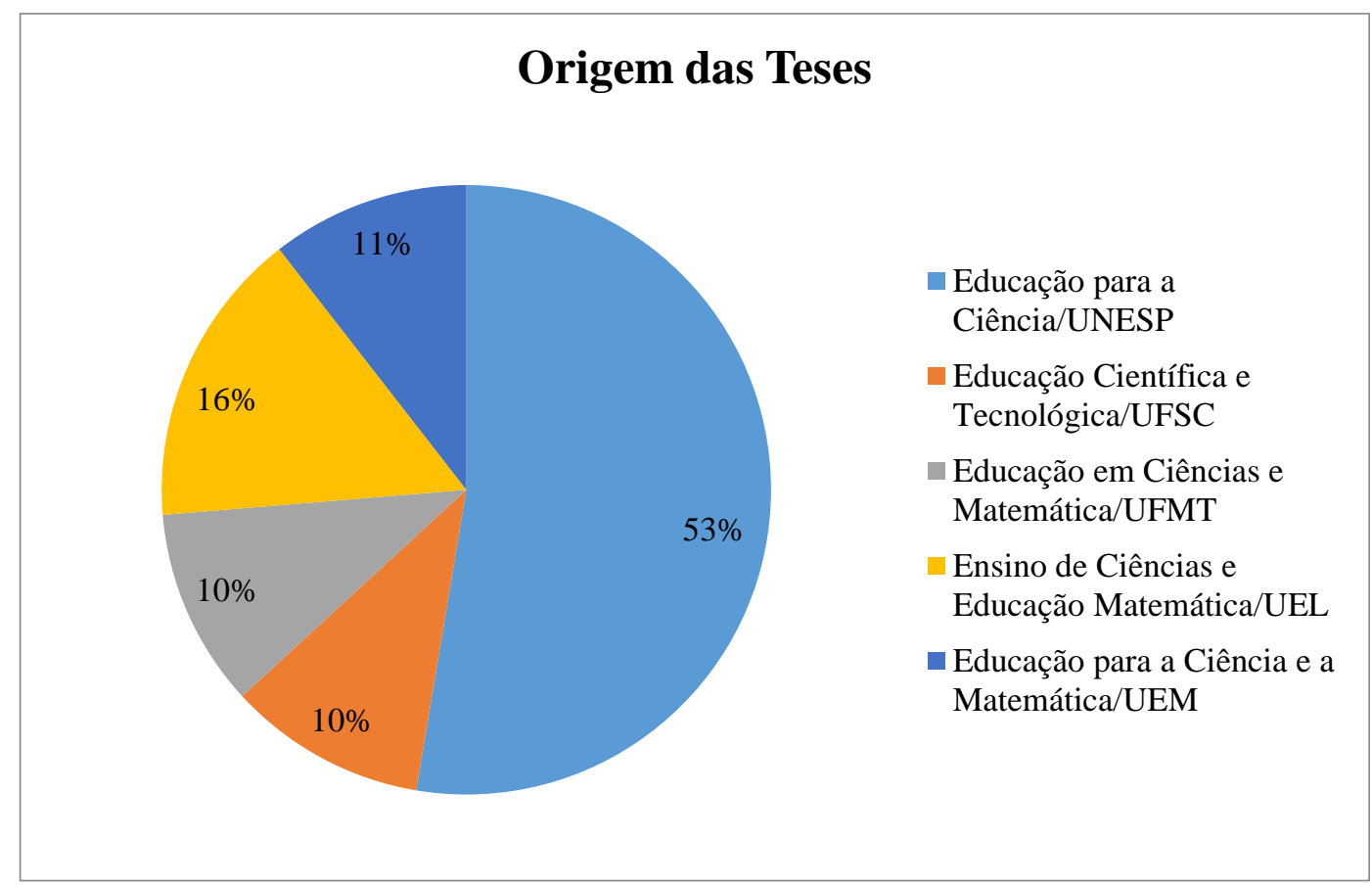

Figura 1 - Teses analisadas conforme IES/Programa.

Fonte: Costa (2017)

Teixeira \& Megid Neto (2012), ao realizarem o levantamento de dissertações e teses referente ao período de 1972-2004 sobre a pesquisa em ensino de Biologia no Brasil ressaltaram:

Está aí um dado preocupante referente à distribuição irregular das pesquisas do ponto de vista geográfico, caracterizando no período estudado, a centralidade das regiões Sul e Sudeste, principalmente desta última. Entendemos que tal distribuição não contempla os interesses regionais vinculados a outras localidades do país, e que a criação de programas específicos de pós-graduação em Ensino de Ciências nas regiões Norte, Nordeste e Centro-Oeste, contribuirá para a reversão desse quadro, ou pelo menos para tornar a produção dessas regiões mais significativa dentro do

Revista REAMEC, Cuiabá - MT, V. 6, n. Especial, dez 2018, ISSN: 2318-6674

Revista do Programa de Doutorado da Rede Amazônica de Educação em Ciências e Matemática

http://periodicoscientificos.ufmt.br/ojs/index.php/reamec 


\section{REVISTA REAMEC}

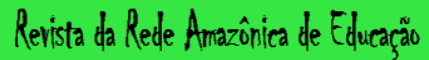

em Ciências e Matemática
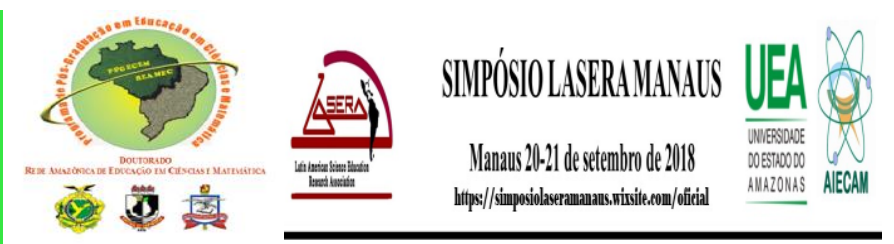

cenário acadêmico nacional. Assim, estudos futuros que agreguem dados referentes há anos mais recentes poderão sinalizar alguma alteração positiva nessa distribuição.

Conforme levantamento realizado neste estudo ainda é notável que a distribuição da produção acadêmica continue discrepante, quando comparada entre as regiões brasileiras. Mesmo após a criação de novos programas de doutoramento, em Ensino/Educação em Ciências, estudos voltados para a Formação de Professores de Biologia, apresentam apenas uma pequena parte da produção das teses, demonstrando o interesse dos pesquisadores para outras linhas de pesquisa que abordem propostas relacionadas às áreas do programa de pós-graduação no qual estejam inseridos, diferente da que está sendo destacada neste artigo.

Do material analisado, de acordo com o Figura 2, obteve-se um total de 15 teses que apresentaram abordagem metodológica qualitativa e apenas 04 que seguiram os padrões da metodologia quali-quantitativa, ou mista, como citado no corpo dos trabalhos por seus autores, e em nenhuma das produções foram encontradas a abordagem quantitativa.

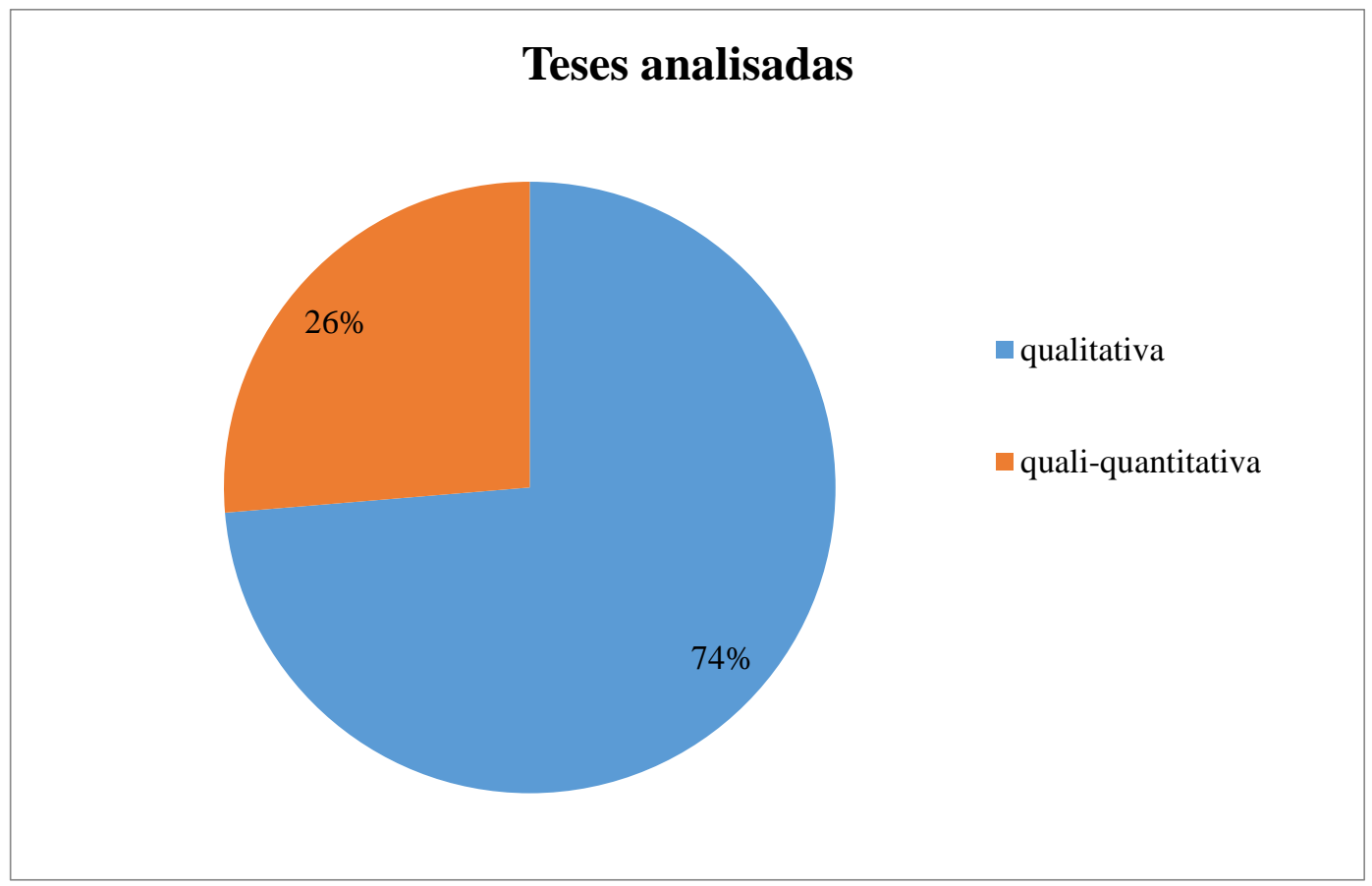

Figura 2 - Teses analisadas conforme IES/Programa.

Fonte: Costa (2017)

A maioria das pesquisas realizadas tanto na Educação em Ciências, quanto no Ensino de Ciências, tem privilegiado a abordagem qualitativa, provavelmente por possibilitar ao 
pesquisador, através de técnicas e ferramentas, o contato direto com seu objeto de pesquisa, bem como ao seu campo de ação.

André (2001) avalia que a abordagem qualitativa para a aquisição de dados descritivos, quando adquiridos da relação direta do pesquisador com o objeto da pesquisa, pode ressaltar mais o processo do que o produto, interessando-se em demonstrar o ponto de vista dos participantes. Assim, a peculiaridade dos objetivos propostos nas teses, juntamente com a inserção do pesquisador no campo de pesquisa, pôde proporcionar sua proximidade com os indivíduos que vivenciam o campo de ação da pesquisa.

Por outro lado, a pesquisa denominada do tipo mista, ou seja, que abrange tanto a abordagem qualitativa, quanto à quantitativa, tem aparecido em alguns trabalhos, porém, de modo ainda tímido, como pode ser analisado neste levantamento. Esse tipo de abordagem além do que já apresentado acima em relação à qualitativa, apresenta também as coletas e os dados de maneira quantitativa, usando principalmente instrumentos de estatística para a análise dos dados.

Sampieri, Collado \& Lucio (2006) expõem que dependendo dos métodos utilizados nas abordagens quantitativas e qualitativas podem ocorrer à conversão dos dados quantitativos em qualitativos e vice-versa. Pois, como a abordagem mista envolve a utilização das outras abordagens metodológicas, possibilita que as diferentes perguntas da investigação sejam respondidas, em conformidade com o planejamento do problema da pesquisa científica. Assim, os autores descrevem as características da pesquisa mista como sendo um processo que analisa e vincula dados tanto qualitativos, quanto quantitativos em uma mesma pesquisa ou, até mesmo a uma série de investigações, no intuito de responder aos questionamentos do problema científico levantado.

\subsection{O que foi pesquisado}

Nas teses analisadas cerca de $63 \%$ optaram por aprofundar suas pesquisas na formação inicial de professores de biologia, e destas $85 \%$ utilizaram a abordagem qualitativa e apenas $15 \%$ a mista.

Em relação à formação continuada de professores de biologia, em apenas $11 \%$ das teses esse foi o objeto de estudo, e em todas foram utilizadas a abordagem qualitativa. 
Em 21\% do material averiguado, não foi exposto claramente, nem no título da tese e nem nas palavras-chaves, se o trabalho referia-se a formação inicial ou continuada e, destes, a metade dos trabalhos utilizou a abordagem qualitativa e a outra metade a quanti-qualitativa. Porém, em apenas 5\% dos trabalhos foi indicado no título, que a pesquisa referia-se a formação inicial ou continuada dos professores de biologia, e estes fizeram uso da metodologia qualitativa.

\title{
3.2 A escolha dos paradigmas
}

Dentre os paradigmas propostos para as pesquisas científicas tem-se o positivista ou quantitativo, o interpretativo ou qualitativo e o sociocrítico ou hermenêutico. Segundo Coutinho (2011) o paradigma é o sistema de princípios, crenças e valores que norteiam a metodologia e baseia as suas concepções numa dada epistemologia.

Assim, acreditamos que os paradigmas devem ser previamente definidos pelo pesquisador antes de iniciar sua pesquisa, e ele deve ter claramente decidido o que pretende pesquisar, e quais os resultados que busca, para então fazer acertadamente a escolha do paradigma que vai utilizar em sua pesquisa científica. Pois, segundo Creswell (2010):

\begin{abstract}
Com frequência a distinção entre pesquisa qualitativa e quantitativa é estruturada em termos do uso de palavras (qualitativa) em vez de números (quantitativa), ou do uso de questões fechadas (hipóteses quantitativas) em vez de questões abertas (questões de entrevista qualitativa). Uma maneira mais completa de encarar as gradações das diferenças entre elas está nas suposições filosóficas básicas que os pesquisadores levam para o estudo, nos tipos de estratégias de pesquisa utilizados em toda a pesquisa (p. ex., experimentos quantitativos ou estudos de caso qualitativos) e nos métodos específicos empregados na condução destas estratégias (p. ex., coleta quantitativa dos dados em instrumentos versus coleta de dados qualitativos através da observação de um ambiente).
\end{abstract}

No material analisado, a maioria dos pesquisadores fez uso do paradigma qualitativo, mesmo sem citar o termo paradigma, mas, outros termos que muitas vezes são utilizados equivocadamente. Em geral essa falha ocorre, porque muitos dos pesquisadores não têm afinidade ou conhecimentos aprofundados sobre os paradigmas, e por isso, preferem não aprofundar no desconhecido, a fim de evitar erros futuros. Porém, ao se omitirem provocam mais erros ainda, pois acabam por conduzir de maneira conturbada suas pesquisas, que certamente apresentarão resultados equivocados ou diferentes do que se espera.

No geral, apenas quatro trabalhos utilizaram o paradigma sociocrítico, neste caso também, nota-se a timidez dos pesquisadores em aprofundar-se no novo, pois muitas vezes, 


\section{REVISTA REAMEC}

Revista da Rede Amazônica de Eduração

em Ciências e Matemática
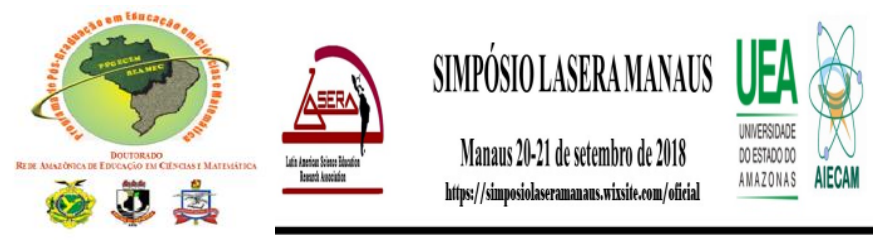

eles confundem as metodologias de suas pesquisas, pois, por apenas utilizarem gráficos ou tabelas com alguns números, acreditam que já estão realizando uma pesquisa mista. Mas, na verdade esse paradigma além do uso desses elementos também permite ao pesquisador propor mudanças conforme o resultado obtido, pois o pesquisador quando opta por tal paradigma deve fazer parte do meio, ou seja, conhece profundamente seu objeto de estudo e, seu campo de ação deve fazer parte de seu cotidiano.

Nesse sentido, Kalhil \& Teixeira (2015) afirmam que:

A pesquisa em educação sempre foi permeada por questões paradigmáticas que geram dúvidas sobre qual método utilizar na abordagem. O pesquisador inicia sua pesquisa sem saber qual método utilizar e, só depois descobre se é quantitativo, qualitativo ou ambos. A abordagem quantitativa é uma abordagem positivista que estabelece uma separação entre o sujeito e o objeto de pesquisa, buscando uma neutralidade entre ambos, pois o pesquisador não se envolve com o objeto pesquisado, este método de pesquisa é uma realidade externa.

Conforme Sampieri, Collado \& Lucio (2006), são as ideias que originam as investigações, inicialmente sem se importar em que tipo de paradigma fundamentará o estudo ou enfoque que será abrangido posteriormente. Para os autores, sempre será necessário primeiramente uma ideia para dar início a pesquisa, pois afirmam desconhecer o substituto de uma "boa ideia", por acreditarem que são justamente as ideias iniciais que irão estabelecer a escolha do paradigma. Pois, dependendo para onde os rumos das investigações tenderem, deverão ser feita a escolha do paradigma, ou seja, se os rumos forem para a realidade objetiva, a pesquisa se firmará na perspectiva quantitativa; porém se a pesquisa for norteada pela realidade subjetiva, deverá ser apoiada na perspectiva qualitativa.

Kalhil \& Teixeira (2015) recomendam que além das observações, é necessário que o pesquisador inclua nos seus estudos leituras que complementem sua pesquisa. Pois, acreditam que o pesquisador não pode prender-se ao reducionismo, e este não pode acreditar que o que está em uso por outros pesquisadores não pode mudar, aceitando que os paradigmas existentes sejam inalteráveis e que a realidade seja simples e incomensurável.

Pelo contrário, o pesquisador deve procurar alternativas para conduzir sua pesquisa e complementá-la, a fim de alcançar com êxito seus objetivos e resultados esperados. Porém, para que isso aconteça, torna-se essencial que haja durante todas as fases da pesquisa a relação sujeito-objeto. Pois, Gamboa \& Santos (2002) enfatizam a necessidade do relacionamento do 
pesquisador com seu objeto de estudo, a fim de que ele possa compreender em sua totalidade o objeto pesquisado, para que depois haja o entendimento dos elementos do todo.

\section{CONCLUSÃo}

Neste artigo, buscou-se conhecer os paradigmas usados na pesquisa científica nos cursos de pós-graduação em Educação em Ciências no Brasil, foi possível examinar as principais metodologias utilizadas na pesquisa. Permitindo-nos detectar a existência de diversas nomenclaturas para designar o paradigma.

Notou-se que a grande a maioria dos trabalhos resultantes dos cursos de doutorados, de onde as teses foram obtidas, priorizavam o uso da pesquisa qualitativa, juntamente com suas técnicas e instrumentos.

Cada tipo de metodologia possui uma finalidade específica, que precisa estar em conformidade com os objetivos propostos no projeto inicial, não é indicado que seja escolhida aleatoriamente, mas o pesquisador necessita conhecer e compreender os paradigmas que serão escolhidos, para que seu trabalho seja concluído com êxito.

O acesso e a realização de estudos com estes moldes poderão contribuir positivamente na formação de estudantes e pesquisadores, pois, analisando criteriosamente os trabalhos realizados, será possível desenvolver critérios metodológicos que poderão auxiliar na identificação de lacunas em sua própria pesquisa, principalmente em relação aos paradigmas que serão utilizados.

\section{REFERÊNCIAS}

ANDRÉ, Marli (org.). O papel da pesquisa na formação e na prática dos professores. Campinas, SP: Papirus, 2001. (Série Prática Pedagógica).

CRESWELL, John W. Projeto de pesquisa: Métodos qualitativo, quantitativo e misto. Tradução Magda Lopes consultoria, supervisão e revisão técnica desta edição Dirceu da Silva - $3^{\text {a }}$ ed. - Porto Alegre: Artmed 2010.

AZEVEDO, Rosa Oliveira Marins. GHEDIN, Evandro. SILVA-FORSBERG, Maria Clara. GONZAGA, Amarildo Menezes. Formação inicial de professores da educação básica no 
Brasil: trajetória e perspectivas. Rev. Diálogo Educ., Curitiba, v. 12, n. 37, p. 997-1026, set./dez. 2012.

COUTINHO, C. (2011). Paradigmas, Metodologias e Métodos de Investigação. In: Metodologias de Investigação em Ciências Sociais e Humanas. (p.9-41).Lisboa. Almedina.

FERREIRA, Norma Sandra de Almeida. As pesquisas denominadas "estado da arte". Educação \& Sociedade, São Paulo, ano 23, n. 79, p.257-272, ago. 2002. Disponível em: http://www.scielo.br/pdf/es/v23n79/10857.pdf. Acesso em 25/03/2017.

Gamboa, S. S. \& Santos, F. J. C. D. (Org.). Pesquisa educacional: quantidade-qualidade. São Paulo: Cortez. $25^{\text {a }}$ Ed. 2002.

KALHIL, Josefina Barrera. TEIXEIRA, Hebert José Balieiro. Múltiplos olhares da pesquisa em educação. Latin American Journal of Science Education. LASERA. 2015.

MEGID NETO, J. e D. PACHECO. Pesquisas sobre o ensino de Física no nível médio no Brasil: concepção e tratamento de problemas em teses e dissertações. Em: R. Nardi. Pesquisas em ensino de Física (pp. 15-30). São Paulo: Escrituras. 2001.

ROMANOWSKI, Joana Paulin; ENS, Romilda Teodora. As pesquisas denominadas do tipo "estado da arte" em educação. Diálogo Educ., Curitiba, v. 6, n. 19, p. 37-50, set./dez. 2006. Disponível em: http://alfabetizarvirtualtextos.files.wordpress.com/2011/08/as-pesquisasdenominadas-do-tipo-estado-da-arte-em-educac3a7c3a3o.pdf Acesso em 25/03/2017.

SAMPIERI, Roberto Hernandez. COLLADO, Carlos Fernandez. LUCIO, Pilar Baptista. Metodologia de la investigacion. McGRAW-HILL/INTERAMERICANA EDITORES, SA DE C.V. $4^{\text {a }}$ edição. 2006.

SILVA, Francisca Jocineide da Costa e. CARVALHO, Maria Eulina Pessoa de. O estado da arte das pesquisas educacionais sobre gênero e educação infantil: uma introdução. $18^{\circ}$ REDOR. Tema: Perspectiva feminista de gênero: desafios no campo das militâncias e das práticas. Universidade Federa Rural d Pernambuco, 2014.

SOARES, M. Pesquisa em educação no Brasil: continuidades e mudanças. Um caso exemplar: a pesquisa sobre alfabetização. Perspectiva, 24, 2, 393-417. 2006.

TEIXEIRA, Paulo Marcelo Marini. MEGID NETO, Jorge. O estado da arte da pesquisa em ensino de Biologia no Brasil: um panorama baseado na análise de dissertações e teses. Revista Electrónica de Enseñanza de las Ciencias Vol. 11, º², 273-297. 2012. 